\title{
Inappropriate ICD Shocks in Pediatric and Congenital Heart Disease Patients
}

\author{
JASON M. GARNREITER, MD ${ }^{1}$ \\ ${ }^{1}$ Department of Pediatrics, Saint Louis University School of Medicine, St. Louis, MO, USA.
}

\begin{abstract}
Although implantable cardioverter-defibrillators (ICDs) have proven to be life-saving devices, there are frequent complications associated with their use, especially in the pediatric and congenital heart disease populations. Inappropriate shocks are a particularly frequent complication in these groups. This review discusses the causes and implications of inappropriate ICD shocks, and presents potential interventions that may assist in safely reducing the rates of inappropriate shocks in pediatric and congenital heart disease patients with ICDs.
\end{abstract}

KEYWORDS. Congenital heart disease, implantable cardioverter-defibrillator, inappropriate shock, pediatric.
ISSN 2156-3977 (print) ISSN 2156-3993 (online) CC BY 4.0 license

(C) 2017 Innovations in Cardiac Rhythm Management

\section{Introduction}

Since the original description of the use of an implantable cardioverter-defibrillator (ICD) in a human, ${ }^{1}$ the use of ICDs has expanded rapidly. In this time, numerous large, prospective studies involving adult patients have demonstrated that these devices can provide significant survival benefits for patients with a history of a cardiac arrest event (as a secondary prevention method), or in those deemed to be at high risk of experiencing a cardiac arrest event due to underlying cardiovascular disease (as a primary prevention method). ${ }^{2-7}$ Pediatric patients and patients with congenital heart disease (CHD) represent a small minority of ICD recipients, and there have been no prospective randomized trials of ICD use in this heterogeneous population. ${ }^{8,9}$ Still, numerous retrospective studies have demonstrated a survival benefit associated with ICD use in this population as well. ${ }^{10-14}$

Nevertheless, despite their clear use-associated benefits in many situations, ICDs are far from perfect. The potential for numerous complications exists, including infection, vascular occlusions, and lead and/or device

The author reports no conflicts of interest or funding received for the published content.

Manuscript received May 3, 2017. Final version accepted July 18, 2017.

Address correspondence to: Jason M. Garnreiter, MD, 1465 S. Grand Blvd., St. Louis, MO 63104, USA.

E-mail: garnreiterjm@slu.edu. malfunction, to name only a few. Additionally, pediatric and some CHD patients have a higher experience rate of many of these complications than healthy adult patients, due in part to the former's younger age, smaller size, more active lifestyle, growth over time, and anatomic constraints. ${ }^{11,15}$ In particular, pediatric and CHD ICD patients experience inappropriate ICD shocks at a rate much higher than that in other patient groups, with most studies indicating that at least $20 \%$ of pediatric and CHD patients experience this phenomenon, ${ }^{14}$ a rate nearly double that observed in some large studies involving adult patients. ${ }^{18}$ This review discusses the importance of addressing inappropriate shocks in pediatric and CHD populations, and presents potential management options for reducing their frequency.

\section{Implications of inappropriate shocks}

An inappropriate shock (IS) is an ICD shock delivered for a reason other than for a potentially life-threatening ventricular tachycardia (VT) or ventricular fibrillation (VF) event (Figure 1). The causes of inappropriate shocks are variable, and include sinus tachycardia, supraventricular tachycardia (SVT), lead fracture, T-wave oversensing, and external noise. These can be painful and disturbing events for patients to experience. Adult patients receiving an IS have been shown to have increasing perceptions of pain and increased consideration of device inactivation, in comparison to those receiving appropriate shocks alone, ${ }^{17}$ 

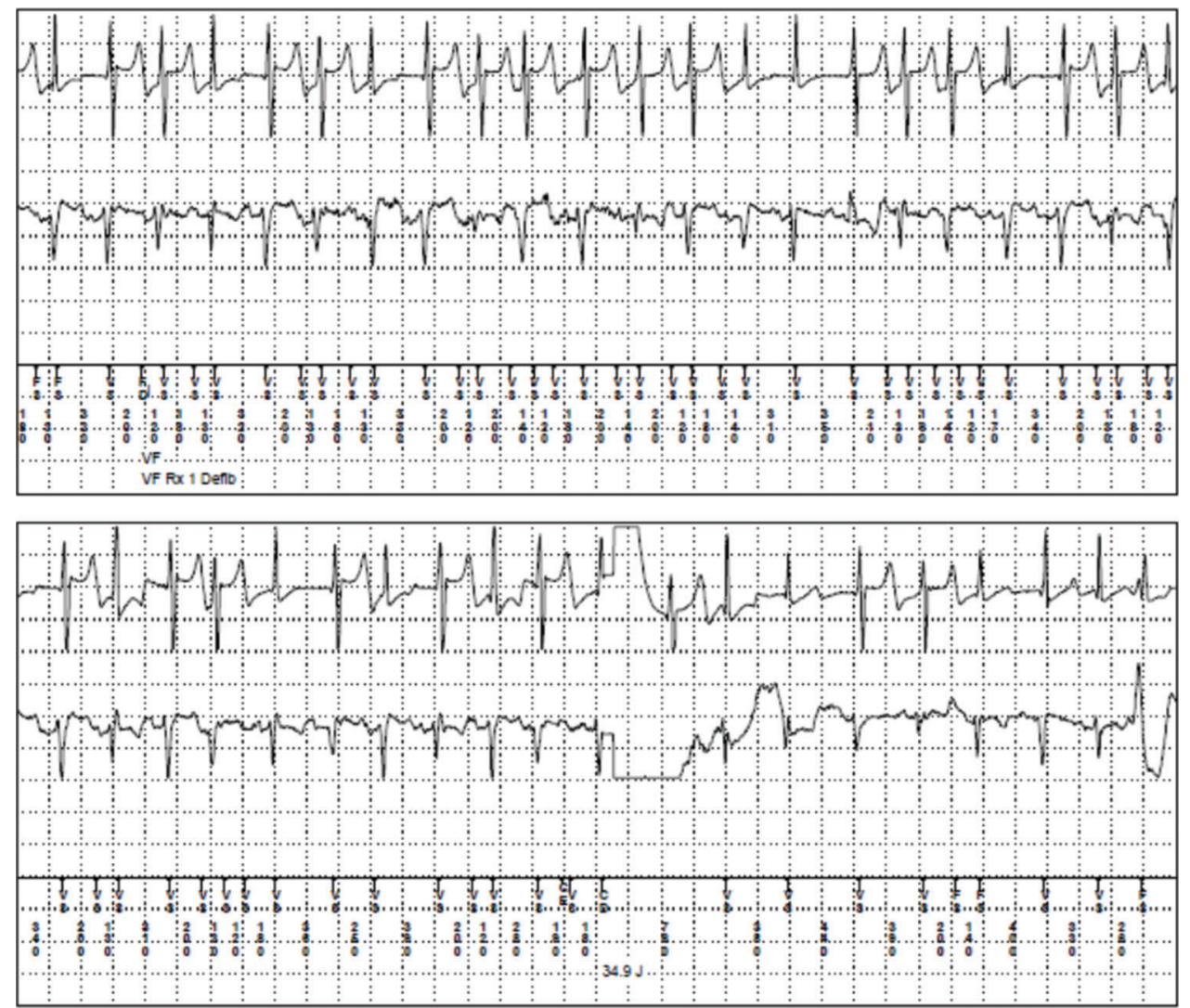

Figure 1: Inappropriate shock as a result of oversensing noise on the RV lead. Top electrogram is RV tip to RV ring; bottom electrogram is can to RV coil.

although this correlation has not been clarified in pediatric or CHD patients. ${ }^{18-21}$ An increased number of shocks has also been associated with increased anxiety, depression, and psychological stress. ${ }^{22-24}$ Additionally, the delivery of shocks has a detrimental effect on device battery longevity; an increased number of shocks delivered means a quicker reduction in total battery life, potentially necessitating device replacement at an earlier point in time.

Not only do inappropriate shocks cause painful episodes that adversely affect quality of life, but also they have been associated with negative clinical outcomes. Analyses of the MADIT-II and SCD-HeFT data first demonstrated an independent association between IS and a twofold increase in mortality in adult patients. ${ }^{16,25}$ A similar association has been subsequently demonstrated in other studies, ${ }^{26,27}$ and supported by two recent meta-analyses. ${ }^{28,29}$ The data from these studies conflict, however, with those from another meta-analysis that demonstrated equivocal results, and other recent studies that found no association between IS and mortality. ${ }^{30,31}$

The underlying cause of this assumption has not been completely elucidated. As discussed by Li et al. in their review, it is unclear if inappropriate shocks cause myocardial damage or are pro-arrhythmic in such a way as to contribute directly to this increased mortality, or if they are merely a marker of more significant underlying cardiovascular disease. ${ }^{32}$ The latter explanation is supported by data from the ALTITUDE study, which demonstrated increased mortality in those patients receiving inappropriate shocks for AF or atrial flutter, but not in those patients receiving inappropriate shocks for sinus tachycardia or noise/artifact. ${ }^{33}$

Although inappropriate shocks are a significant problem for ICD patients in general, they are an even more common problem in the pediatric and CHD population. In larger adult studies, the rate of IS has been reported to range from $10 \%$ to $15 \% .{ }^{16,25,27}$ However, most studies of ICD use in pediatric and CHD patients have found rates of IS to be between $20 \%$ and $30 \%$ in these patient populations, ${ }^{10,11,13,14,34-40}$ with some studies observing IS in up to $40 \%$ to $50 \%$ of patients and, in some instances, with inappropriate shocks being more frequent than appropriate shocks. ${ }^{12,19,41,42}$ This is likely a result of a more active lifestyle, faster rates of sinus tachycardia, longer duration of implantation, smaller patient size, and a higher rate of device and lead complications relative to adult patients. ${ }^{11,15}$

Inappropriate shocks are painful events that confer no benefit to patients, are associated with worsened psychosocial and clinical outcomes, and are particularly frequent in the pediatric and CHD ICD populations. Because inappropriate shocks are known to be a significant clinical problem in this population, every effort should be made to reduce their frequency without compromising patient safety. 


\section{Interventions to reduce rates of inappropriate shock}

Inappropriate shocks are clearly a significant problem in pediatric and CHD ICD patients, and safely reducing their frequency seems to be an obvious goal. Tools that can help accomplish this can be broken down into two subsets: non-device-based interventions, and device-based interventions.

\section{Non-device-based interventions}

Antiarrhythmic medications. Treatment with antiarrhythmic medications has the potential to decrease appropriate shocks by decreasing ventricular arrhythmias, and may also reduce the frequency of inappropriate shocks by reducing supraventricular arrhythmias and blunting maximal rates of sinus tachycardia. A prospective placebo-controlled trial in adult ICD patients demonstrated a reduction in shocks from treatment with sotalol therapy ${ }^{43}$ in comparison with treatment with $\beta$-blockers alone. ${ }^{44}$ Data from the MADIT-CRT study found reduced shocks in patients treated with carvedilol versus metoprolol. ${ }^{45}$ Despite this, antiarrhythmic medications are not commonly used in adult ICD patients, with the National Cardiovascular Data Registry ICD registry demonstrating that only $15 \%$ of adult ICD patients were discharged on antiarrhythmic medication. ${ }^{46}$

The rate of antiarrhythmic medication use in pediatric and CHD patients appears to be higher than that seen in adult patients. Most studies have found that at least 40\%, and up to $100 \%$, of patients are on antiarrhythmic medications, primarily $\beta$-blockers. ${ }^{10,13,39-41,47-49}$ This may be a reflection of the different substrates present in the pediatric and CHD population, particularly channelopathy patients, in whom $\beta$-blockers are a mainstay of treatment. The use of antiarrhythmic medication has not been conclusively demonstrated to reduce the level of shock burden in this population, despite the common practice of altering medical management in patients who receive shocks. ${ }^{36}$ However, the high baseline rate of antiarrhythmic medication use makes this a difficult association to find in the absence of a randomized trial.

Notably, in the absence of more conclusive data in this population, the use of antiarrhythmic medications, particularly $\beta$-blockers, is common practice, and is a reasonable recommendation to include in a shock-reduction protocol.

Cardiac ablation. Ablation has long been used as part of shock-reduction protocols to provide targeted elimination of supraventricular or ventricular tachyarrhythmias. The SMASH-VT study found that the ablation of VT in adult patients post-myocardial infarction reduced the number of patients receiving appropriate ICD shocks from $33 \%$ to $12 \%$, without increasing mortality. ${ }^{50}$ The VTACH study found that prophylactic VT ablation in adult patients with coronary artery disease reduced appropriate shocks from $47 \%$ to $29 \%$, again without increasing mortality. ${ }^{51}$ These studies demonstrate the ability to reduce appropriate shocks by reducing VT substrates in adults with coronary artery disease. Although not specifically evaluated in ICD patients, several studies have demonstrated successful ablation of VT in patients with repaired CHD, predominantly tetralogy of Fallot and Mustard/Senning patients. ${ }^{52,53}$

However, the ability to reduce inappropriate shocks by eliminating SVT substrates has not been well studied, particularly in the pediatric and CHD populations. In the absence of specific data to guide clinical decisionmaking, for patients with known SVT, or those receiving an IS for SVT, an ablation would seem to be a reasonable approach to reducing inappropriate shock, provided that there are no contraindications to the performance of the procedure.

\section{Device-based interventions-data from studies in adult patients}

Although non-device-based interventions are a useful component of a shock-reduction strategy, appropriate device programming can have a significant impact on shock burden. Early in the experience with ICD programming, focus was placed on delivering shock therapy rapidly. However, over time, it became clear that this aggressive strategy resulted in unnecessary shocks, both appropriate and inappropriate, and a number of ICD programming interventions began to be studied in adult populations in an effort to reduce the shock burden. These interventions primarily fall into three categories: alterations to detection rate or duration programming, use of antitachycardia pacing (ATP), and utilization of discriminator algorithms to more accurately exclude non-ventricular arrhythmias.

\section{Alterations in detection rate or duration programming.}

The most intuitive programming intervention to reduce shock burden is alterations in tachyarrhythmia detection, either by increasing the tachycardia detection rate or the time to tachycardia detection. An early study to evaluate this was the PREPARE study, which prospectively evaluated 700 patients imbued with a specific more lenient programming strategy (including a VT detection rate of $182 \mathrm{bpm}$ ), in comparison with patients in the EMPIRIC and MIRACLE ICD trials, which considered more conventional programming. Not surprisingly, the lenient programming resulted in a significant reduction in shocks; however, interestingly, there was also no increase in mortality or morbidity, which had been one of the arguments against a more lenient programming strategy. ${ }^{54}$ A similar result was demonstrated for prolonged detection intervals in the RELEVANT study. ${ }^{55}$ In one of the more significant studies on the issue, MADITRIT reported on outcomes using lenient programming strategies. One thousand five hundred primary prevention patients were randomized to one of three programming options: conventional therapy ( $>170 \mathrm{bpm}$ VT zone with 2.5 -s delay to shock, and $>200 \mathrm{bpm}$ with a 1.0-s delay); high rate therapy (>200 bpm 2.5-s delay); and delayed therapy ( $>170 \mathrm{bpm}$ with a 60 -s delay, $>200 \mathrm{bpm}$ with a 12 -s delay, and $>250 \mathrm{bpm}$ with a 2.5-s delay). Both the 
delayed therapy and high rate therapy programming strategies were associated with decreased rates of appropriate and inappropriate shocks, and with a decrease in all-cause mortality by approximately $50 \%$, with no increase in the rates of syncope. ${ }^{56,57}$ These studies had a significant impact on ICD programming strategies, and spawned a number of similar studies examining variations on lenient programming practices. Several studies have examined high rate programming, ${ }^{58,59}$ while others have considered prolonged detection, ${ }^{6,-65}$ or a combination of these two approaches. ${ }^{66,67}$ In general, lenient programming practices in these studies have demonstrated a decrease in the rate of appropriate and inappropriate shocks, with either a decrease in overall mortality or no difference, when compared to conventional programming practices. These practices have been further solidified in two meta-analyses, which found lenient programming practices were associated with a reduction in mortality and IS rates without an increase in syncope. ${ }^{68,69}$ It is clear that in these populations, adopting lenient programming strategies is a safe and effective way to reduce shocks.

Use of ATP. In addition to these programming strategies, ATP is also frequently used as part of shock reduction protocols (Figure 2). Although the ability to terminate VT using ATP is well known, the use of ATP was minimized in early clinical trials out of safety concerns. In the PainFREE Rx II study, 634 adult patients were randomized to undergo either ATP first or shock first for fast
VT detection. ATP was found to be effective in over $70 \%$ of episodes, and there was no increase in the rates of syncope, sudden death, or arrhythmia acceleration in the ATP group. ${ }^{70}$ A similar reduction in shock burden without a compromise in safety was demonstrated in the EMPIRIC trial. ${ }^{71}$ These findings suggest that the use of ATP is an important programming component as part of a shock reduction protocol. However, the success of ATP likely depends on the substrate present, and its success rates in younger patients, and in channelopathy patients in particular (who were excluded from the PainFREE Rx II study), have not been well studied. Limited data suggest that two sequences are more effective than one, and that 15 sequences are no better than eight. ${ }^{72,73}$

Use of discriminator algorithms. Various programmable discriminators have been utilized to reduce shock burden by attempting to improve identification of sinus tachycardia and SVT that may fall within the programmed VT/VF zones, and withhold therapies. These discriminators are heterogeneous, and details vary depending on the device manufacturer and model. These primarily evaluate either arrhythmia timing (the abruptness of onset, stability, or duration) or the morphology of the electrogram relative to stored templates during sinus rhythm. The primary argument against the use of these options has been concerns that their use would lead to a delay in or the withholding of treatment for true VT/VF. However, the use of discriminators has been shown to

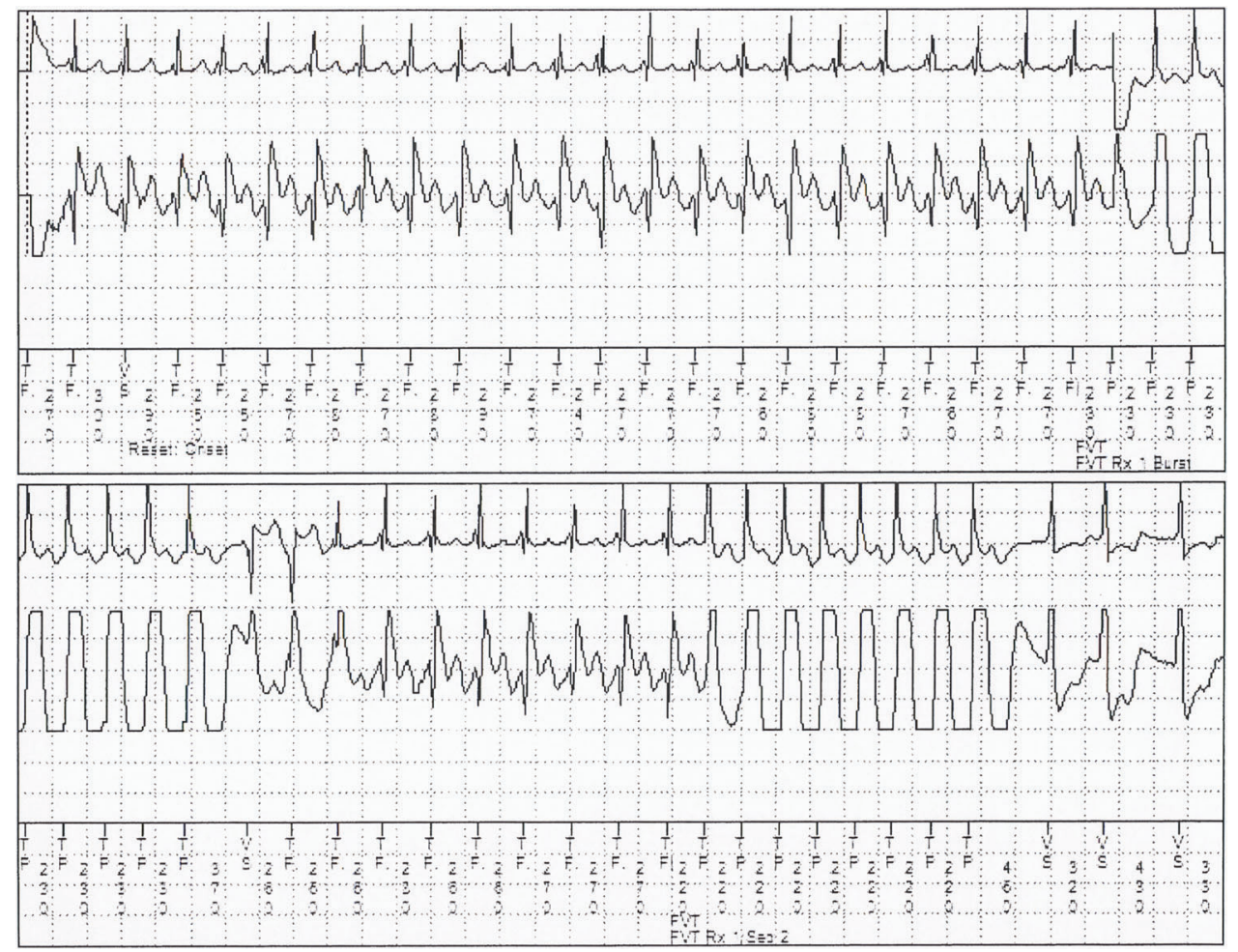

Figure 2: Ventricular tachycardia terminated by the second round of ventricular ATP. Top electrogram is RV tip to RV ring; bottom electrogram is can to RV coil. 
decrease the rate of inappropriate shocks without compromising appropriate therapy or increasing mortality as compared with rate-only programming. ${ }^{74,75}$ Nevertheless, relative to other programming parameters, there are fewer studies that directly evaluate the safety and reliability of discriminators, and the variety and heterogeneity of these parameters makes it difficult to determine their optimal use in clinical management.

A subset of these algorithms attempts to use information from the atrial lead in dual-chamber devices to better discriminate between VT/VF and SVT or sinus tachycardia, primarily based on the $\mathrm{A} / \mathrm{V}$ relationships and timing. Data on the results of these algorithms are mixed, with some studies demonstrating a decrease in the rate of inappropriate shocks in dual-chamber ICD patients, ${ }^{76}$ and others finding no difference. ${ }^{77} \mathrm{~A}$ meta-analysis on the subject was also equivocal, finding a small reduction in the total number of inappropriate shocks delivered in dual-chamber ICDs, but no reduction in the number of patients experiencing an episode of inappropriate shock..$^{78}$ In the absence of more convincing data, and given the potential for increased costs and complications associated with the presence of an additional lead, it seems that the addition of an atrial lead should be reserved for those patients with an indication for atrial pacing.

\section{Device-based interventions in pediatric and CHD patients}

Data from studies in adult patients have demonstrated that device-based programming strategies can reduce the rates of IS without compromising safety, and a recent consensus statement provides recommendations for ICD programming in the adult population. ${ }^{79}$ However, despite the high rates of IS in pediatric and CHD patients, there are few studies that have been published that evaluate programming practices in this population. A study by Love et al. evaluating 54 ICD patients reported a rate of IS of $15 \%$ caused by either SVT or sinus tachycardia. They noted a lower programmed rate for shock therapy in the group that received an IS (186 bpm versus $200 \mathrm{bpm}$ ) that was statistically significant. For those patients receiving an IS, a number of interventions were undertaken, including increasing VT detection rate and duration, and increasing the dose of antiarrhythmic medications. According to the study results, none of these patients went on to experience another IS, although the specific details of the programming changes were not reported. The study's authors also noted the rare use of SVT discriminator algorithms as an institutional practice at the time. They conclude that setting a ventricular detection rate above the maximum expected sinus rate may be a reasonable approach to minimizing the rate of IS. ${ }^{80}$ In 2015, we published a single-center retrospective review of 144 patients, and reported a rate of IS under $10 \%$ using a general institutional practice of programming relatively high detection rates and long detection durations. Specifically, mean tachycardia detection rate was $222 \mathrm{bpm}$, and mean detection duration was 18 beats. Although patients with shocks programmed in a VT zone were more likely to experience an IS, an association with detection rates or durations and IS could not be made, given that patients were programmed fairly similarly. No episodes of syncope or undertreated VT/VF were identified. $^{48}$ The practice of programming higher detection rates would seem consistent with data that have demonstrated higher detected ventricular tachycardia rates in the CHD population relative to the general adult population. Khairy et al. reported data from tetralogy of Fallot and transposition of the great arteries patient populations, demonstrating detection rates in patients receiving an appropriate shock of $213 \mathrm{bpm}$ and $222 \mathrm{bpm}$, respectively. ${ }^{34,81}$ Additionally, in a population of ICD patients with Brugada syndrome, the mean detected tachycardia rate in appropriate shocks was $335 \mathrm{bpm}$, with the suggestion that a single VF zone at $222 \mathrm{bpm}$ would reduce IS by $70 \%$, although it could potentially lead to the missing of appropriate shocks in $1.7 \%$ of patients. ${ }^{82}$

The frequency of use of ATP and its effectiveness in this population is not well known, although some authors have found the success rate to be low, and have advocated against its routine use. ${ }^{37}$ However, in a single-center study of 79 pediatric and CHD patients, ATP was successful at terminating VT in $88 \%$ of episodes, with $85 \%$ of episodes being terminated within the first ATP attempt. Acceleration of the VT with ATP was seen in three episodes (3\%), which either spontaneously terminated, were terminated by additional ATP, or were converted by a shock in one case each. ATP was similarly effective in patients with CHD and cardiomyopathy, but not effective in patients with primary electrical disease. One episode of proarrhythmia from inappropriate ATP was reported, which was terminated with a shock. ${ }^{43}$

The utility of dual-chamber discriminator algorithms to reduce the rates of IS has been investigated in pediatric and CHD patients. In a multi-center study by Lawrence et al. of 168 ICD patients, $21 \%$ of whom received an IS, there was no difference in the rate of IS or appropriate shocks between single- and dual-chamber devices, suggesting that the presence of an atrial lead does not enhance rhythm discrimination in this population, a finding that was supported by our single-center report as well. ${ }^{48,83}$ These data again support the notion that the addition of an atrial lead should be reserved for those patients with a specific pacing indication, rather than for instances of enhanced rhythm discrimination alone.

\section{Summary of programming recommendations}

In the absence of a significant body of published literature to guide programming decisions in the pediatric and CHD ICD populations, clinicians are left to (1) interpret what we can from the limited published data, (2) extrapolate with caution from the literature on adult patients, and (3) rely on clinical experience and expert recommendations. ${ }^{84}$ As is true for many aspects of caring for this heterogeneous population, a "one-size-fitsall" approach is overly simplistic, and preset device "nominal" settings (based on the typical adult patient) are often inappropriate. Programming practices must be 
Table 1: Pediatric and CHD ICD Programming Considerations

\begin{tabular}{|c|c|c|}
\hline 1. & Individualize programming & $\begin{array}{l}\text { Programming should be individualized for each patient. The use of } \\
\text { pre-programmed "nominal" settings is rarely appropriate. }\end{array}$ \\
\hline 2. & Be proactive & $\begin{array}{l}\text { Consider implementing programming strategies aimed at decreasing } \\
\text { inappropriate shocks at the time of implant, rather than waiting for an } \\
\text { IS to happen in order to adopt these strategies. }\end{array}$ \\
\hline 3. & $\begin{array}{l}\text { Program faster } \\
\text { detection rates }\end{array}$ & $\begin{array}{l}\text { If rates of spontaneously hemodynamically significant VT/VF are known, } \\
\text { detection should be programmed below this rate. In the absence of known } \\
\text { slow VT, programming therapy should be avoided at rates below the } \\
\text { expected maximal sinus rate, at least } 200 \mathrm{bpm} \text { in most patients and } \\
>220 \mathrm{bpm} \text { in many patients, especially those who are younger. }\end{array}$ \\
\hline 4. & $\begin{array}{l}\text { Program longer } \\
\text { detection times }\end{array}$ & $\begin{array}{l}\text { Perform this at a minimum of } 18 / 24 \text { beats in most patients, with strong } \\
\text { consideration of } 24 / 32 \text { or } 30 / 40 \text { intervals. }\end{array}$ \\
\hline 5. & $\begin{array}{l}\text { Utilize ATP where } \\
\text { applicable }\end{array}$ & $\begin{array}{l}\text { ATP appears to be minimally effective in most channelopathy patients, } \\
\text { in whom ventricular arrhythmias are not typically pace-terminable, and } \\
\text { should therefore be avoided. In patients with cardiomyopathies or CHD, } \\
\text { ATP should be programmed either before or, at minimum, during charging. } \\
\text { At least two sequences of ATP should be employed in most situations. }\end{array}$ \\
\hline 6. & $\begin{array}{l}\text { Utilize SVT discriminators } \\
\text { when appropriate }\end{array}$ & $\begin{array}{l}\text { Deactivate in patients with AV block, who cannot conduct SVT rapidly. } \\
\text { Otherwise, the use of discriminators is reasonable, especially if therapies } \\
\text { are programmed on for slower zones (ie, }<220 \text { bpm for younger patients, } \\
<200 \text { bpm in older patients and adults). If used, the "time out" functions } \\
\text { should be disabled, to prevent the delivery of therapy for a prolonged } \\
\text { SVT episode. }\end{array}$ \\
\hline 7. & $\begin{array}{l}\text { Implant single chamber } \\
\text { devices as default }\end{array}$ & $\begin{array}{l}\text { The addition of an atrial lead should be reserved only for patients with } \\
\text { an indication for a dual-chamber system, and not for the purpose of } \\
\text { improving tachycardia detection alone. }\end{array}$ \\
\hline 8. & $\begin{array}{l}\text { Encourage antiarrhythmic } \\
\text { medications }\end{array}$ & $\begin{array}{l}\text { Do this especially with } \beta \text {-blockers, which can reduce IS by reducing rates } \\
\text { of sinus tachycardia and the incidence of SVT. }\end{array}$ \\
\hline 9. & Consider SVT ablation & $\begin{array}{l}\text { Contemplate this in patients with a known history of SVT (depending on } \\
\text { underlying anatomical considerations), or for patients who receive an IS } \\
\text { for SVT, especially if it is not controlled with medications. }\end{array}$ \\
\hline
\end{tabular}

individualized to the specific patient and clinical situation. However, certain general recommendations can be made that are applicable in many-though not all-situations, with the goal of safely reducing the rate of IS. Table 1 provides some considerations to keep in mind when assessing and working with a pediatric or CHD ICD patient.

\section{Conclusions}

ICDs are effective devices for use in treating pediatric and CHD patients at risk for life-threatening ventricular arrhythmias. However, the rates of device complications in these individuals can be excessive, with inappropriate shocks in particular representing a significant problem. There are a number of both non-device-based and device-based interventions that have the potential to significantly decrease the rates of IS in these patient populations, without compromising safety. Additional data are needed to evaluate the outcomes of these strategies in real-world settings in pediatric and CHD ICD patients.

\section{References}

1. Mirowski M, Reid PR, Mower MM, et al. Termination of malignant ventricular arrhythmias with an implanted automatic defibrillator in human beings. $N$ Engl J Med. 1980;303(6):322-324.
2. Bardy GH, Lee KL, Mark DB, et al. Amiodarone or an implantable cardioverter-defibrillator for congestive heart failure. N Engl J Med. 2005;352(3):225-237.

3. Moss AJ, Hall WJ, Cannom DS, et al. Improved survival with an implanted defibrillator in patients with coronary disease at high risk for ventricular arrhythmia. Multicenter Automatic Defibrillator Implantation Trial Investigators. N Engl J Med. 1996;335(26):1933-1940.

4. Kadish A, Dyer A, Daubert JP, et al. Prophylactic defibrillator implantation in patients with nonischemic dilated cardiomyopathy. N Engl J Med. 2004;350(21):2151-2158.

5. Antiarrhythmics versus Implantable Defibrillators (AVID) Investigators. A comparison of antiarrhythmic-drug therapy with implantable defibrillators in patients resuscitated from near-fatal ventricular arrhythmias. N Engl J Med. 1997; 337(22):1576-1583.

6. Moss AJ, Zareba W, Hall WJ, et al. Prophylactic implantation of a defibrillator in patients with myocardial infarction and reduced ejection fraction. N Engl J Med. 2002;346(12):877-883.

7. Bigger JT Jr. Prophylactic use of implanted cardiac defibrillators in patients at high risk for ventricular arrhythmias after coronary-artery bypass graft surgery. Coronary Artery Bypass Graft (CABG) Patch Trial Investigators. N Engl J Med. 1997;337(22):1569-1575.

8. Czosek RJ, Meganathan K, Anderson JB, Knilans TK, Marino BS, Heaton PC. Cardiac rhythm devices in the pediatric population: utilization and complications. Heart Rhythm. 2012;9(2):199-208.

9. Burns KM, Evans F, Kaltman JR. Pediatric ICD utilization in the United States from 1997 to 2006. Heart Rhythm. 2011;8(1):23-28.

10. Silka MJ, Kron J, Dunnigan A, Dick M. Sudden cardiac death and the use of implantable cardioverter-defibrillators 
in pediatric patients. The Pediatric Electrophysiology Society. Circulation. 1993;87(3):800-807.

11. Alexander ME, Cecchin F, Walsh EP, Triedman JK, Bevilacqua LM, Berul CI. Implications of implantable cardioverter defibrillator therapy in congenital heart disease and pediatrics. J Cardiovasc Electrophysiol. 2004;15(1):72-76.

12. Gradaus R, Wollmann C, Kobe J, et al. Potential benefit from implantable cardioverter-defibrillator therapy in children and young adolescents. Heart. 2004;90(3):328-329.

13. Maron BJ, Spirito P, Ackerman MJ, et al. Prevention of sudden cardiac death with implantable cardioverterdefibrillators in children and adolescents with hypertrophic cardiomyopathy. J Am Coll Cardiol. 2013;61(14):1527-1535.

14. Berul CI, Van Hare GF, Kertesz NJ, et al. Results of a multicenter retrospective implantable cardioverter-defibrillator registry of pediatric and congenital heart disease patients. J Am Coll Cardiol. 2008;51(17):1685-1691.

15. Atallah J, Erickson CC, Cecchin F, et al. Multi-institutional study of implantable defibrillator lead performance in children and young adults: results of the Pediatric Lead Extractability and Survival Evaluation (PLEASE) study. Circulation. 2013;127(24):2393-2402.

16. Daubert JP, Zareba W, Cannom DS, et al. Inappropriate implantable cardioverter-defibrillator shocks in MADIT II: frequency, mechanisms, predictors, and survival impact. I Am Coll Cardiol. 2008;51(14):1357-1365.

17. Marcus GM, Chan DW, Redberg RF. Recollection of pain due to inappropriate versus appropriate implantable cardioverter-defibrillator shocks. Pacing Clin Electrophysiol. 2011; 34(3):348-353.

18. Bedair R, Babu-Narayan SV, Dimopoulos K, et al. Acceptance and psychological impact of implantable defibrillators amongst adults with congenital heart disease. Int J Cardiol. 2015;181:218-224.

19. Czosek RJ, Bonney WJ, Cassedy A, et al. Impact of cardiac devices on the quality of life in pediatric patients. Circ Arrhythm Electrophysiol. 2012;5(6):1064-1072.

20. DeMaso DR, Lauretti A, Spieth L, et al. Psychosocial factors and quality of life in children and adolescents with implantable cardioverter-defibrillators. Am J Cardiol. 2004;93(5): 582-587.

21. Sears SF, Hazelton AG, St Amant J, et al. Quality of life in pediatric patients with implantable cardioverter defibrillators. Am J Cardiol. 2011;107(7):1023-1027.

22. Sears SF, Jr., Todaro JF, Lewis TS, Sotile W, Conti JB. Examining the psychosocial impact of implantable cardioverter defibrillators: a literature review. Clinical Cardiol. 1999; 22(7):481-489.

23. Mark DB, Anstrom KJ, Sun JL, et al. Quality of life with defibrillator therapy or amiodarone in heart failure. $N$ Engl J Med. 2008;359(10):999-1008.

24. Noyes K, Corona E, Veazie P, Dick AW, Zhao H, Moss AJ. Examination of the effect of implantable cardioverterdefibrillators on health-related quality of life: based on results from the Multicenter Automatic Defibrillator Trial-II. Am J Cardiovasc Drugs. 2009;9(6):393-400.

25. Poole JE, Johnson GW, Hellkamp AS, et al. Prognostic importance of defibrillator shocks in patients with heart failure. N Engl J Med. 2008;359(10):1009-1017.

26. van Rees JB, Borleffs CJW, de Bie MK, et al. Inappropriate implantable cardioverter-defibrillator shocks: incidence, predictors, and impact on mortality. J Am Coll Cardiol. 2011;57(5): $556-562$.

27. Ruwald AC, Schuger C, Moss AJ, et al. Mortality reduction in relation to implantable cardioverter defibrillator programming in the Multicenter Automatic Defibrillator
Implantation Trial-Reduce Inappropriate Therapy (MADITRIT). Circ Arrhythm Electrophysiol. 2014;7(5):785-792.

28. Proietti R, Labos C, Davis M, et al. A systematic review and meta-analysis of the association between implantable cardioverter-defibrillator shocks and long-term mortality. Can J Cardiol. 2015;31(3):270-277.

29. Alba AC, Braga J, Gewarges M, Walter SD, Guyatt GH, Ross HJ. Predictors of mortality in patients with an implantable cardiac defibrillator: a systematic review and meta-analysis. Can J Cardiol. 2013;29(12):1729-1740.

30. Sun S, Johnson J, Degroot P, Brown ML, Obel O. Effect of ICD therapies on mortality in the OMNI trial. J Cardiovasc Electrophysiol. 2016;27(2):192-199.

31. Tompkins CM, McNitt S, Polonsky B, et al. Sex differences in inappropriate ICD device therapies: MADIT-II and MADIT-CRT. J Cardiovasc Electrophysiol. 2017;28(1):94-102.

32. Li A, Kaura A, Sunderland N, Dhillon PS, Scott PA. The significance of shocks in implantable cardioverterdefibrillator recipients. Arrhythm Electrophysiol Rev. 2016; 5(2):110-116.

33. Powell BD, Saxon LA, Boehmer JP, et al. Survival after shock therapy in implantable cardioverter-defibrillator and cardiac resynchronization therapy-defibrillator recipients according to rhythm shocked. I Am Coll Cardiol. 2013; 62(18):1674-1679.

34. Khairy P, Harris L, Landzberg MJ, et al. Implantable cardioverter-defibrillators in tetralogy of Fallot. Circulation. 2008;117(3):363-370.

35. Olde Nordkamp LR, Postema PG, Knops RE, et al. Implantable cardioverter-defibrillator harm in young patients with inherited arrhythmia syndromes: a systematic review and meta-analysis of inappropriate shocks and complications. Heart Rhythm. 2016;13(2):443-454.

36. Kamp AN, Von Bergen NH, Henrikson CA, et al. Implanted defibrillators in young hypertrophic cardiomyopathy patients: a multicenter study. Pediatr Cardiol. 2013;34(7): 1620-1627.

37. Lewandowski M, Sterlinski M, Maciag A, et al. Long-term follow-up of children and young adults treated with implantable cardioverter-defibrillator: the authors' own experience with optimal implantable cardioverter-defibrillator programming. Europace. 2010;12(9):1245-1250.

38. Santharam S, Hudsmith L, Thorne S, Clift P, Marshall H, De Bono J. Long-term follow-up of implantable cardioverterdefibrillators in adult congenital heart disease patients: indications and outcomes. Europace. 2017;19(3):407-413.

39. Aykan HH, Karagoz T, Gulgun M, et al. Midterm results of implantable cardioverter defibrillators in children and young adults from a single center in Turkey. Pacing Clin Electrophysiol. 2016;39(11):1225-1239.

40. Roses-Noguer F, Jarman JW, Clague JR, Till J. Outcomes of defibrillator therapy in catecholaminergic polymorphic ventricular tachycardia. Heart Rhythm. 2014;11(1):58-66.

41. Korte T, Koditz H, Niehaus M, Paul T, Tebbenjohanns J. High incidence of appropriate and inappropriate ICD therapies in children and adolescents with implantable cardioverter defibrillator. Pacing Clin Electrophysiol. 2004;27(7): 924-932.

42. Kalra Y, Radbill AE, Johns JA, Fish FA, Kannankeril PJ. Antitachycardia pacing reduces appropriate and inappropriate shocks in children and congenital heart disease patients. Heart Rhythm. 2012;9(11):1829-1834.

43. Pacifico A, Hohnloser SH, Williams JH, et al. Prevention of implantable-defibrillator shocks by treatment with sotalol. d,l-Sotalol Implantable Cardioverter-Defibrillator Study Group. N Engl J Med. 1999;340(24):1855-1862. 
44. Connolly SJ, Dorian P, Roberts RS, et al. Comparison of beta-blockers, amiodarone plus beta-blockers, or sotalol for prevention of shocks from implantable cardioverter defibrillators: the OPTIC Study: a randomized trial. JAMA. 2006;295(2):165-171.

45. Ruwald $\mathrm{MH}, \mathrm{Abu}$-Zeitone $\mathrm{A}$, Jons $\mathrm{C}$, et al. Impact of carvedilol and metoprolol on inappropriate implantable cardioverter-defibrillator therapy: the MADIT-CRT trial (Multicenter Automatic Defibrillator Implantation With Cardiac Resynchronization Therapy). J Am Coll Cardiol. 2013; 62(15):1343-1350/

46. Dev S, Peterson PN, Wang Y, Curtis JP, Varosy PD, Masoudi FA. Prevalence, correlates, and temporal trends in antiarrhythmic drug use at discharge after implantable cardioverter defibrillator placement (from the National Cardiovascular Data Registry [NCDR]). Am J Cardiol. 2014; 113(2):314-320

47. Yap SC, Roos-Hesselink JW, Hoendermis ES, et al. Outcome of implantable cardioverter defibrillators in adults with congenital heart disease: a multi-centre study. Eur Heart J. 2007;28(15):1854-1861.

48. Garnreiter JM, Pilcher TA, Etheridge SP, Saarel EV. Inappropriate ICD shocks in pediatrics and congenital heart disease patients: risk factors and programming strategies. Heart Rhythm. 2015;12(5):937-942.

49. Jin BK, Bang JS, Choi EY, et al. Implantable cardioverter defibrillator therapy in pediatric and congenital heart disease patients: a single tertiary center experience in Korea. Korean J Pediatr. 2013;56(3):125-129.

50. Reddy VY, Reynolds MR, Neuzil P, et al. Prophylactic catheter ablation for the prevention of defibrillator therapy. N Engl J Med. 2007;357(26):2657-2665.

51. Kuck KH, Schaumann A, Eckardt L, et al. Catheter ablation of stable ventricular tachycardia before defibrillator implantation in patients with coronary heart disease (VTACH): a multicentre randomised controlled trial. Lancet. 2010; 375(9708):31-40.

52. Therrien J, Siu SC, Harris L, et al. Impact of pulmonary valve replacement on arrhythmia propensity late after repair of tetralogy of Fallot. Circulation. 2001;103(20): 2489-2494.

53. Kapel GF, Reichlin T, Wijnmaalen AP, et al. Re-entry using anatomically determined isthmuses: a curable ventricular tachycardia in repaired congenital heart disease. Circ Arrhythm Electrophysiol. 2015;8(1):102-109.

54. Wilkoff BL, Williamson BD, Stern RS, et al. Strategic programming of detection and therapy parameters in implantable cardioverter-defibrillators reduces shocks in primary prevention patients: results from the PREPARE (Primary Prevention Parameters Evaluation) study. J Am Coll Cardiol. 2008;52(7):541-550.

55. Gasparini M, Menozzi C, Proclemer A, et al. A simplified biventricular defibrillator with fixed long detection intervals reduces implantable cardioverter defibrillator (ICD) interventions and heart failure hospitalizations in patients with non-ischaemic cardiomyopathy implanted for primary prevention: the RELEVANT [Role of long dEtection window programming in patients with LEft VentriculAr dysfunction, Non-ischemic eTiology in primary prevention treated with a biventricular ICD] study. Eur Heart J. 2009. 30(22):2758-2767.

56. Moss AJ, Schuger C, Beck CA, et al. Reduction in inappropriate therapy and mortality through ICD programming. N Engl J Med. 2012;367(24):2275-2283.

57. Kutyifa V, Daubert JP, Schuger C, et al. Novel ICD programming and inappropriate ICD therapy in CRT-D versus
ICD Patients: a MADIT-RIT sub-study. Circ Arrhythm Electrophysiol. 2016;9(1):e001965.

58. Clementy N, Challal F, Marijon E, et al. Very high rate programming in primary prevention patients with reduced ejection fraction implanted with a defibrillator: Results from a large multicenter controlled study. Heart Rhythm. 2017; 14(2):211-217.

59. Cay S, Canpolat U, Ucar F, et al. Programming implantable cardioverter-defibrillator therapy zones to high ranges to prevent delivery of inappropriate device therapies in patients with primary prevention: results from the RISSYICD (Reduction of Inappropriate ShockS bY InCreaseD zones) trial. Am J Cardiol. 2015;115(9):1235-1243.

60. Mastenbroek MH, Pedersen SS, van der Tweel I, Doevendans PA, Meine M. Results of ENHANCED implantable cardioverter defibrillator programming to reduce therapies and improve quality of life (from the ENHANCED-ICD study). Am J Cardiol. 2016;117(4):596-604.

61. Gasparini M, Proclemer A, Klersy C, et al. Effect of longdetection interval vs standard-detection interval for implantable cardioverter-defibrillators on antitachycardia pacing and shock delivery: the ADVANCE III randomized clinical trial. JAMA. 2013;309(18):1903-1911.

62. Kloppe A, Proclemer A, Arenal A, et al. Efficacy of long detection interval implantable cardioverter-defibrillator settings in secondary prevention population: data from the Avoid Delivering Therapies for Nonsustained Arrhythmias in ICD Patients III (ADVANCE III) trial. Circulation. 2014; 130(4):308-314.

63. Noro M, Zhu X, Takagi T, et al. Evaluation of defibrillation safety and shock reduction in implantable cardioverterdefibrillator patients with increased time to detection: A randomized SANKS study. J Arrhythm. 2015;31(2):94-100.

64. Sterns LD, Meine M, Kurita T, et al. Extended detection time to reduce shocks is safe in secondary prevention patients: The secondary prevention substudy of PainFree SST. Heart Rhythm. 2016;13(7):1489-1496.

65. Arenal A, Proclemer A, Kloppe A, et al. Different impact of long-detection interval and anti-tachycardia pacing in reducing unnecessary shocks: data from the ADVANCE III trial. Europace. 2016;18(11):1719-1725.

66. Saeed M, Hanna I, Robotis D, et al. Programming implantable cardioverter-defibrillators in patients with primary prevention indication to prolong time to first shock: results from the PROVIDE study. J Cardiovasc Electrophysiol. 2014; 25(1):52-59.

67. Hayashi Y, Takagi M, Kakihara J, et al. Safety and efficacy of high-rate cutoff and long detection interval ICD programming in secondary prevention patients. Heart Vessels. 2017; 32(2):175-185.

68. Tan VH, Wilton SB, Kuriachan V, Sumner GL, Exner DV. Impact of programming strategies aimed at reducing nonessential implantable cardioverter defibrillator therapies on mortality: a systematic review and meta-analysis. Circ Arrhythm Electrophysiol. 2014;7(1):164-170.

69. Scott PA, Silberbauer J, McDonagh TA, Murgatroyd FD. Impact of prolonged implantable cardioverter-defibrillator arrhythmia detection times on outcomes: a meta-analysis. Heart Rhythm. 2014;11(5):828-835.

70. Wathen MS, DeGroot PJ, Sweeney MO, et al. Prospective randomized multicenter trial of empirical antitachycardia pacing versus shocks for spontaneous rapid ventricular tachycardia in patients with implantable cardioverterdefibrillators: Pacing Fast Ventricular Tachycardia Reduces Shock Therapies (PainFREE Rx II) trial results. Circulation. 2004;110(17):2591-2596. 
71. Wilkoff BL, Ousdigian KT, Sterns LD, et al. A comparison of empiric to physician-tailored programming of implantable cardioverter-defibrillators: results from the prospective randomized multicenter EMPIRIC trial. I Am Coll Cardiol. 2006;48(2):330-339.

72. Anguera I, Dallaglio P, Sabate $X$, et al. The benefit of a second burst antitachycardia sequence for fast ventricular tachycardia in patients with implantable cardioverter defibrillators. Pacing Clin Electrophysiol. 2014;37(4):486-494.

73. Santini M, Lunati M, Defaye P, et al. Prospective multicenter randomized trial of fast ventricular tachycardia termination by prolonged versus conventional anti-tachyarrhythmia burst pacing in implantable cardioverter-defibrillator patients-Atp DeliVery for pAiNless ICD thErapy (ADVANCE-D) Trial results. J Interv Card Electrophysiol. 2010;27(2):127-135.

74. Dorian P, Philippon F, Thibault B, et al. Randomized controlled study of detection enhancements versus rateonly detection to prevent inappropriate therapy in a dualchamber implantable cardioverter-defibrillator. Heart Rhythm. 2004;1(5):540-547.

75. Auricchio A, Schloss EJ, Kurita T, et al. Low inappropriate shock rates in patients with single- and dual/triple-chamber implantable cardioverter-defibrillators using a novel suite of detection algorithms: PainFree SST trial primary results. Heart Rhythm. 2015;12(5):926-936.

76. Kolb C, Sturmer M, Sick P, et al. Reduced risk for inappropriate implantable cardioverter-defibrillator shocks with dual-chamber therapy compared with single-chamber therapy: results of the randomized OPTION study. JACC Heart Fail. 2014;2(6):611-619.

77. Friedman PA, Bradley D, Koestler C, et al. A prospective randomized trial of single- or dual-chamber implantable cardioverter-defibrillators to minimize inappropriate shock risk in primary sudden cardiac death prevention. Europace. 2014;16(10):1460-1468.

78. Theuns DA, Rivero-Ayerza M, Boersma E, Jordaens L. Prevention of inappropriate therapy in implantable defibrillators: A meta-analysis of clinical trials comparing single-chamber and dual-chamber arrhythmia discrimination algorithms. Int J Cardiol. 2008;125(3):352-357.

79. Wilkoff BL, Fauchier L, Stiles MK, et al. 2015 HRS/EHRA/ APHRS/SOLAECE expert consensus statement on optimal implantable cardioverter-defibrillator programming and testing. J Arrhythm. 2016;32(1):1-28.

80. Love BA, Barrett KS, Alexander ME, et al. Supraventricular arrhythmias in children and young adults with implantable cardioverter defibrillators. J Cardiovasc Electrophysiol. 2001; 12(10):1097-1101.

81. Khairy P, Harris L, Landzberg MJ, et al. Sudden death and defibrillators in transposition of the great arteries with intra-atrial baffles: a multicenter study. Circ Arrhythm Electrophysiol. 2008;1(4):250-257.

82. Lee WS, Kim J, Kwon C-H, et al. Tachyarrhythmia cycle length in appropriate versus inappropriate defibrillator shocks in Brugada syndrome, early repolarization syndrome, or idiopathic ventricular fibrillation. Korean Circ J. 2016;46(2):179-185.

83. Lawrence D, Von Bergen $\mathrm{N}$, Law $\mathrm{IH}$, et al. Inappropriate ICD discharges in single-chamber versus dual-chamber devices in the pediatric and young adult population. J Cardiovasc Electrophysiol. 2009;20(3):287-290.

84. Khairy P, Mansour F. Implantable cardioverter-defibrillators in congenital heart disease: 10 programming tips. Heart Rhythm. 2011;8(3):480-483. 